\title{
Indian Journal of Gastroenterology: The promises fulfilled and waiting for fulfillment!
}

\author{
Uday C. Ghoshal ${ }^{1}$
}

Published online: 15 January 2018

(C) Indian Society of Gastroenterology 2018

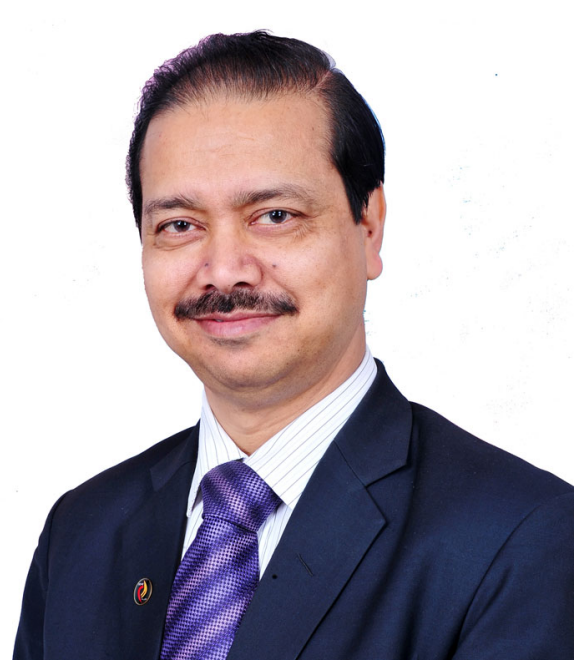

It is a great pleasure for me to take-up the responsibility of the honorary position of the Editor-in-Chief of the Indian Journal of Gastroenterology from Prof. B S Ramakrishna, who served the journal for last 5 years in this position and took it up to newer heights. I promise that I will try my best to take it up further. Promises are the uniquely human way of ordering the future, making it predictable and reliable to the extent that this is humanly possible, Hannah Arendt, a German-born, American political theorist said. In my opinion, in addition to maintenance of the timely peer review and publication, our journal in its current state, has some other priorities.

Uday C. Ghoshal

udayghoshal@gmail.com

1 Department of Gastroenterology, Sanjay Gandhi Postgraduate Institute of Medical Sciences, Lucknow 226 014, India
- Attracting submission of manuscripts of higher quality

- Attracting authors for submission of review articles and consensus on important and unique Asian and Indian issues

- Encouraging Indian gastroenterologists, both seniors, and juniors, in academic Institution and private facilities to contribute to the journal

- Increasing international visibility and recognition

- Increasing citation of the published papers and the impact factor of the journal

To achieve these goals, we need to take up journeys through some pre-defined paths. Increasing the impact factor is one such step. Quality of the manuscripts published and their citation, which determines the impact factor of the journal, go hand in hand. However, with increasing international competition in science, getting high standard articles, particularly for a specialty journal that is not among the most visible journals in the field worldwide, is not easy. Moreover, most experts in the field may not like to volunteer to contribute to a journal that is not an international mainstream journal. Surprisingly, most Indian authorities classify publications in national and international journals (even if the latter is of lower standard!) separately for selection for awards and recognition.

As our out-going Editor-in-Chief mentioned, changing the name of the journal may be a step towards its higher international visibility and recognition among authors, invited authors, experts, and peer reviewers, which may contribute to increasing its impact factor.

Publication of review articles and consensus on important and unique Indian and Asian issues is expected to not only raise the impact factor of the journal but may pave the way towards its inclusion in the Science Citation Index due to the influence of these papers among researchers and clinicians. Attempts towards generating such consensus and practice guidelines are also important to increase the level of the patient care in the country. Hence, it is important that the Indian 
Scientific Societies, particularly the Indian Society of Gastroenterology (ISG), take up the responsibility to organize such consensus and submit these to the journal. I am sure that the current dynamic Secretary General of the ISG, Prof. Govind Makharia, would take up this responsibility. I also wish that in near future, some of the Asian Consensus papers be submitted for consideration for publication in the journal. Moreover, I hope that with support from the publisher, the full text of all the reviews and consensus publications be available online free, which would undoubtedly increase their visibility and citation.

To encourage more and more Indian authors to contribute to the journal requires mentoring and encouraging the young Indian Gastroenterologists, both in the public funded academic Institutions and privately funded facilities to contribute to the science. In fact, clinical research from privately funded facilities is important considering the fact that currently, both in urban and rural areas in India, the main source of health care for $63 \%$ to $70 \%$ of the population is provided by private facilities [1]. However, some of the reasons for lack of contribution in research from this sector is lack of motivation, incentive, lack of fund and time for research, and most importantly, no or inadequate training to design study, analyze the data and manuscript writing. I wish that in future the journal and the societies can jointly organize workshops and training modules to fulfill some of these deficiencies. One other incentive the journal planned to initiate is IJG-ISG Award for the best paper published in the Indian Journal of Gastroenterology in the future.
Since the journal started getting published by the Springer Nature, there is an improvement in its international visibility. But several other strategies need to be initiated to improve it further. These include, support from an Editorial Board that is internationally represented, attracting manuscripts (including invited reviews) of unique national and international importance not only from the Indian but also international authors, starting symposium and oration in the name of the journal during various national and international meetings, promoting the journal in various international conferences, promotion of the journal contents in the various social media, and having a name on the cover of the journal that tend to represent contents on global in addition to local issues to attract wider readership.

I thank the ISG for bestowing me this important responsibility. I hope that with the support from an enhanced Editorial Board, the authors, peer reviewers, Springer Nature, the friend of ISG Mr. Marian D'Souza, the Managing Editor in Mumbai Office, all members of the ISG, national and international friends, I will be able to do justice to this important responsibility. At the end, let me recapitulate, "where there's a will, there is a way".

\section{Reference}

1. Schmulson M, Corazziari E, Ghoshal UC, et al. A four-country comparison of healthcare systems, implementation of diagnostic criteria, and treatment availability for functional gastrointestinal disorders: a report of the Rome foundation working team on cross-cultural, multinational research. Neurogastroenterol Motil. 2014;26:1368-85. 